\title{
Fine Structure of the Young Vegetative Hyphae of Pythium debaryanum
}

\author{
By LILIAN E. HAWKER AND PATRICIA McV. ABBOTT \\ Department of Botany, University of Bristol
}

\section{SUMMARY}

The fine structure of Pythium debaryanum Hesse differs from that of Rhizopus species and some other fungi in the abundant regularly distributed endoplasmic reticulum, the presence of typical Golgi-bodies and the irregularly tubular structure of the cristae mitochondriae. Some of these characters resemble those of some algae and the liverwort Anthoceros and the significance of this is discussed. Typical lomasomes are present.

\section{METHODS}

Young hyphae of Pythium debaryanum Hesse grown on $3 \%$ malt agar for $40 \mathrm{hr}$. at $20^{\circ}$ were fixed with Luft's permanganate (Luft, 1956), embedded in Araldite, sectioned by the methods previously described (Hawker \& Abbot, 1963) and examined and photographed with a Phillips E.M. 200 electron microscope.

\section{RESULTS}

The cell wall shows no structure and is represented only by a narrow electron transparent zone (Pl. 3, fig. 5).

The plasmalemma or ectoplast is represented by a wavy line bounding the endoplasm (Pl. 1, figs. 1 and 2; Pl. 2, fig. 4) and situated just within the wall except where lomasomes $(L)(\mathrm{Pl}$. 2, fig. 4; Pl. 3, fig. 6) are present. These contain amorphous matter and are similar to those shown by Moore \& McAlear (1961) for several fungi.

The endoplasm enclosed within the plasmalemma is of complex nature and shows a regularly distributed reticulum appearing as two outer dark layers and a wider light inner layer ( $E R$ in the photographs). Portions of this reticulum may widen to form irregular cisternae $(C)$ or globules $(G)$. Occasionally these cisternae are stacked together to give typical Golgi-bodies or dictyosomes $(D, \mathrm{Pl}, 1$ and 2 ; Pl. 4, fig. 9) towards the periphery of the endoplasm. The matrix of the endoplasm is homogeneous or slightly granular.

The mitochondria are ovoid with a regular outline. They are surrounded by a membrane appearing as two dark layers enclosing a wider light one. The inner dark layer projects into the interior to form more or less tubular, irregularly shaped cristae $(M C)$. Occasionally the outer membrane of a mitochondrion appears to be continuous with the endoplasmic reticulum (Pl. 3, fig. 6, $z_{3}$ ) and apparently gives rise to small vesicles (Pl. 2, fig. 4), the nature and further development of which could not be determined. The central matrix of the mitochondria resembles that of the endoplasm.

The nuclei are of irregular shape and size. The nuclear membrane is of three layers, an inner light layer enclosed by two thin dark ones, and is interrupted by 
numerous pores (Pl. 3, fig. 6; Pl. 4, fig. 8) and occasionally by larger gaps (Pl. 3, fig. 6). The nuclear membrane shows connexions with the endoplasmic reticulum (Pl. 2, fig. 4; Pl. 3, fig. 6) as has been shown by other workers for a variety of organisms (e.g. Weier \& Thomson, 1962, for leaf mesophyll; Manton, 1961, for the liverwort Anthoceros; Lindergren, 1962, for yeasts). Serial sections suggest that contact occurs only over a limited area of the nuclear membrane.

Vacuoles were not present in young hyphae, but typical stellate vacuoles occurred in older material, finally coalescing to give a large central vacuole in mature hyphae. The endoplasmic reticulum is progressively less regularly arranged as the hyphae age. The mitochondria (Fig. 1) and nuclei remain distinct even in the oldest material examined.

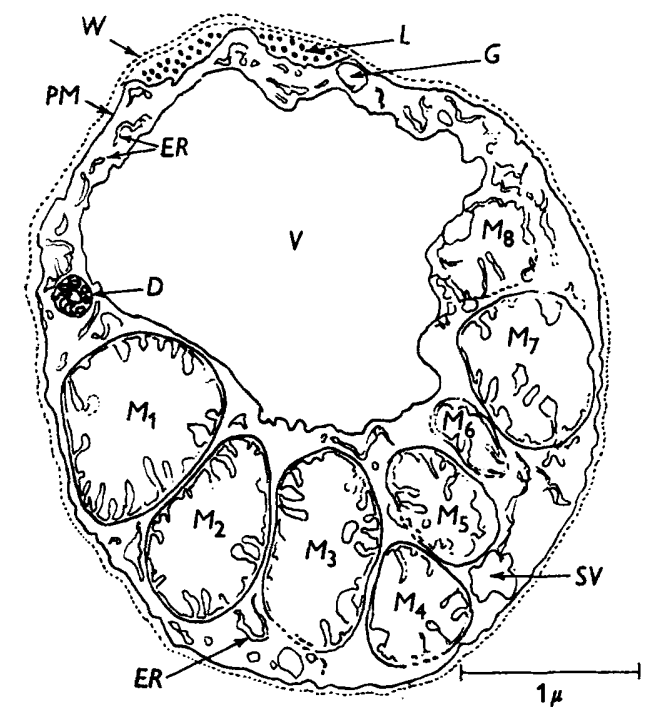

Fig. 1. Tracing of an electron micrograph of a mature hypha of Pythium debaryanum (? permanganate fixed) showing mitochondria $(M)$, possible remains of a Golgi-body $(D)$, unidentified spherical globule $(G)$, endoplasmic reticulum $(E R)$ which is less abundant and less regularly distributed than in the younger hyphae shown in Pls. 1-4, plasmalemma $(P M)$, large vacuole $(V)$ surrounded by tonoplast, small stellate vacuole $(S V)$. Mitochondria $1-3$ are still more or less intact but 4-7 show signs of breakdown. $M_{8}$ is in an advanced state of breakdown. $L=$ lomasome (shown diagrammatically). $W=$ cell wall.

\section{DISCUSSION}

As has already been pointed out (Hawker, 1963) the fine structure of Pythium debaryanum shows many points of resemblance to that of some algae and green plants and differs in some respects from that of species of Rhizopus and other filamentous fungi and yeasts. The absence of visible structure in the cell wall is in marked contrast to material from Rhizopus species fixed in a similar way (Hawker \& Abbott, 1963). This is not surprising in view of the known difference in the chemical nature of the largely cellulose wall of Pythium and the chitinous one of Rhizopus.

The mitochondrial cristae are much less regular in shape and arrangement than those of Rhizopus (Hawker \& Abbott, 1963) or of certain yeasts (Thyagarajan, Conti \& Naylor, 1961). They resemble those of many algae and protozoa and also the irregularly distended ones of the liverwort Anthoceros illustrated by Manton 


\section{Structure of young vegetative hyphae of Pythium debaryanum 493}

(1961, fig. 18). Manton, however, considers that this appearance may be due to osmic distortion and that the cristae of most green algae and plants are normally flat plates. In her figure 17, representing material fixed with potassium permanganate, the cristae are not distended and are more or less plate-like, but even here they are much less regular than those of Rhizopus (Hawker \& Abbott, 1963) which were also fixed with permanganate. The permanganate fixed material of Pythium is, however, very different from similarly fixed material of Rhizopus, the cristae being almost certainly irregularly tubular in contrast to the regular flat plates of Rhizopus. In general the mitochondria of Pythium show at least a superficial resemblance to those of many algae and some green plants and are unlike those shown in published figures of other fungi.

The most striking difference between Pythium and other fungi, e.g. Rhizopus and yeasts, is the regularly distributed endoplasmic reticulum of the former and, in particular, the presence of typical Golgi-bodies resembling those of the Chrysophycean flagellate Paraphysomonas vestita (Manton \& Leedale, 1961) and the liverwort Anthoceros (Manton, 1961). No such highly organized Golgi-bodies were seen in Rhizopus. Moore \& McAlear (1962) observed such structures in Neobulgaria pura only, in a survey of over 50 genera. Thus the fine structure of the fungus Pythium debaryanum resembles that of certain lower green plants in a number of ways, the most striking being the nature of the endoplasmic reticulum. This is of interest taxonomically, since many mycologists consider that the Oomycetes may be closely related to certain green algae. On the other hand the presence of typical lomasomes is a fungal characteristic, since these are thought by Moore \& McAlear (1961) to be found only in fungi.

We are indebted to the Department of Scientific and Industrial Research for a grant in aid of this work.

\section{REFERENCES}

Hawker, L. E. (1963). Fine structure of Pythium debaryanum Hesse. Nature, Lond. 197, 618.

Hawker, L. E. \& Aвbotr, P. McV. (1963). Fine structure of vegetative hyphae of Rhizopus. J. gen. Microbiol. 30, 401.

Lindegren, C. C. (1962). Origin of endoplasmic reticulum. Nature, Lond. 195, 1225.

LUFT, J. H. (1956). Permanganate-a new fixative for electron microscopy. J. biophys. biochem. Cytol. 2, 799.

Manton, I. (1961). Plant cell structure; in Contemporary botanical thought, edited by A. M. McLeod \& L. S. Cobley. Edinburgh: Oliver and Boyd, p. 171.

Manton, I. \& Leedale, G. F. (1961). Observations on the fine structure of Paraphysomonas vestita with special reference to Golgi bodies and the internal origin of scales. Phycologia, 1, 35.

Moore, R. T. \& McAlear, J. H. (1961). Fine structure of Mycota 5. Lomasomespreviously uncharacterized hyphal structures. Mycologia, 53, 194.

Moore, R. T. \& McAlear, J. H. (1962). Characterization of the Golgi dictyosome of the fungus Neobulgaria pura in Rept. Vth Int. Congr. Electron Microscopy. New York: Academic Press.

Thyagarajan, T. R., Conti, S. F. \& Naylor, H. B. (1961). Electron microscopy of yeast mitochondria. Exp. Cell Res. 25, 216.

Weier, T. E. \& Thomson, W. W. (1962). Membranes of mesophyll cells of Nicotiana rustica and Phaseolus vulgaris with particular reference to the chloroplast. Amer. J. Bot. 49, 807 . 
EXPLANATION OF PLATES

Pythium debaryanum-electron micrographs

$W=$ cell wall, $N=$ nucleus, $N M=$ nuclear membrane, $N P=$ pores in nuclear membrane, $\boldsymbol{M}=$ mitochondria, $\boldsymbol{M C}=$ cristae, $\boldsymbol{E R}=$ endoplasmic reticulum, $\boldsymbol{C}=$ cisternae, $\boldsymbol{G}=$ globules, $D=$ Golgi-body or dictyosome, $P M=$ plasmalemma or ectoplast, $L=$ lomasome.

All material fixed Luft's permanganate

\section{Pinates 1 and 2}

Figs. 1 and 2. Slightly oblique serial sections through a young hypha.

Fig. 3. Part of Fig. 1 enlarged. Matrix of nuclei shows faint reticulate structure.

Fig. 4. Same hypha as in Fig. 2 enlarged. Note typical Golgi-bodies. Compare with serial section shown in Fig. 3. Note contact between nuclear membranes and endoplasmic reticulum at point $\boldsymbol{X}$ and compare with same point $x$ in Fig. 3 ; distinct Golgi-body $D_{1}$ and less distinct one $D_{2}$ and compare with same points (marked $d_{1}$ and $d_{2}$ ) in Fig. 1 ; small globose bodies adjacent to mitochondrion at points $Z_{1}, Z_{2}$ and compare with similar detached body at point $z_{1}$ (Fig. 3) and blister-like body apparently being formed by the mitochondrion at $z_{2}$ in Fig. 3 ; changes in form of various globules and cisternae in the two sections; faint reticulate structure of nuclear matrix as in Fig. 8 ; irregular tubular structure of cristae mitochondriae (compare with same mitochondria in Fig. 3).

\section{Plates 3 and 4}

Figs. 5 and 7. Oblique serial sections through another hypha of similar age to that shown in Pls. 1 and 2 and adjacent to it on the grid.

Figs. 6 and 8. Parts of same sections enlarged. Note continuity between nuclear membrane and endoplasmic reticulum at points $R_{1}, R_{2}, R_{3}$ and $R_{4}$ in Fig. 6 and compare with similar points $r_{1}, r_{2}$, $r_{3}$ and $r_{4}$ in Fig. 8 ; large gap in nuclear membrane at $S$ in Fig. 6 and more or less complete membrane at similar position $s$ in Fig. 8 .

Fig. 9. More or less transverse section of part of a third hypha showing a Golgi-body in which some tubules are at right-angles to others. 


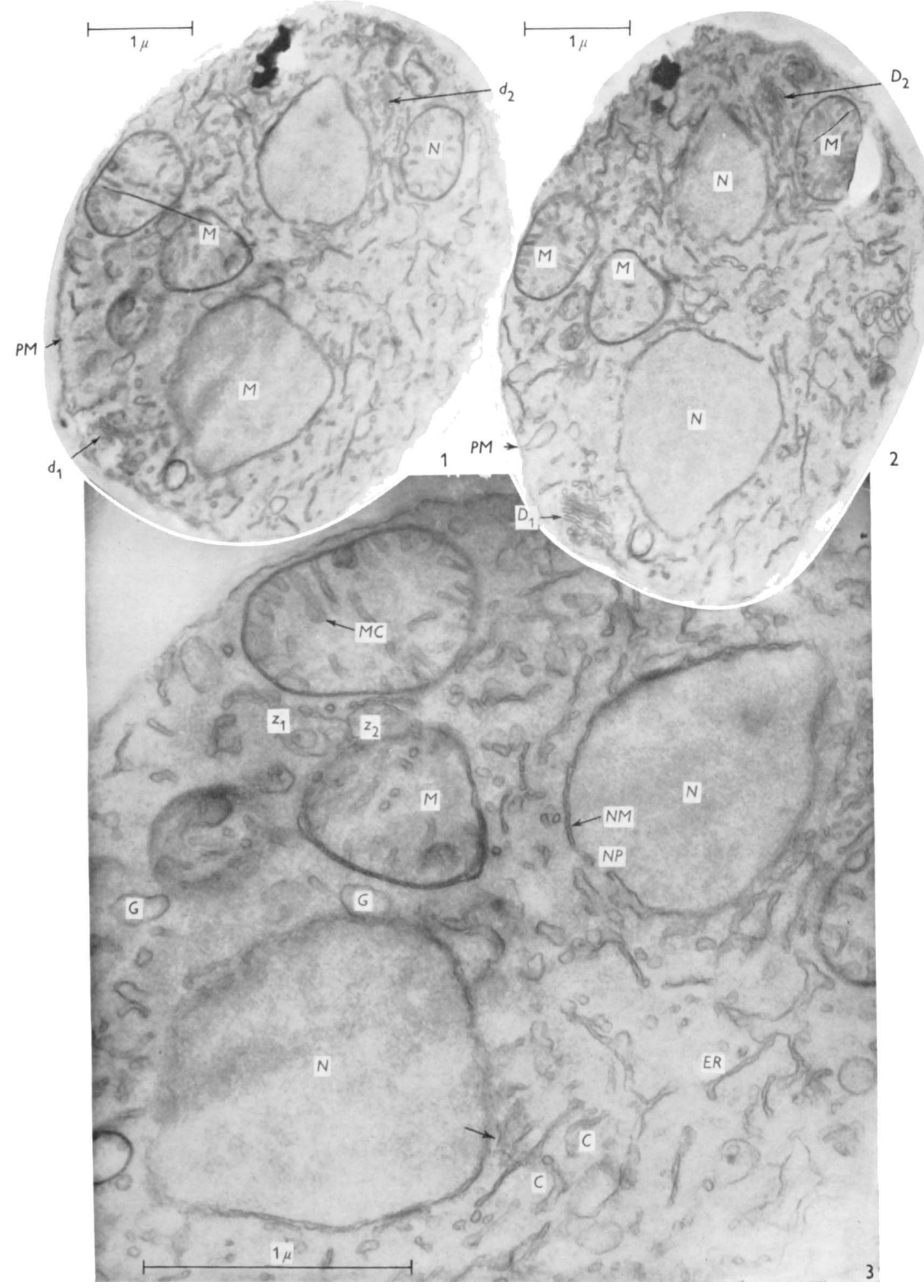


Journal of General Microbiology, Vol. 31, No. 3

Plate 2

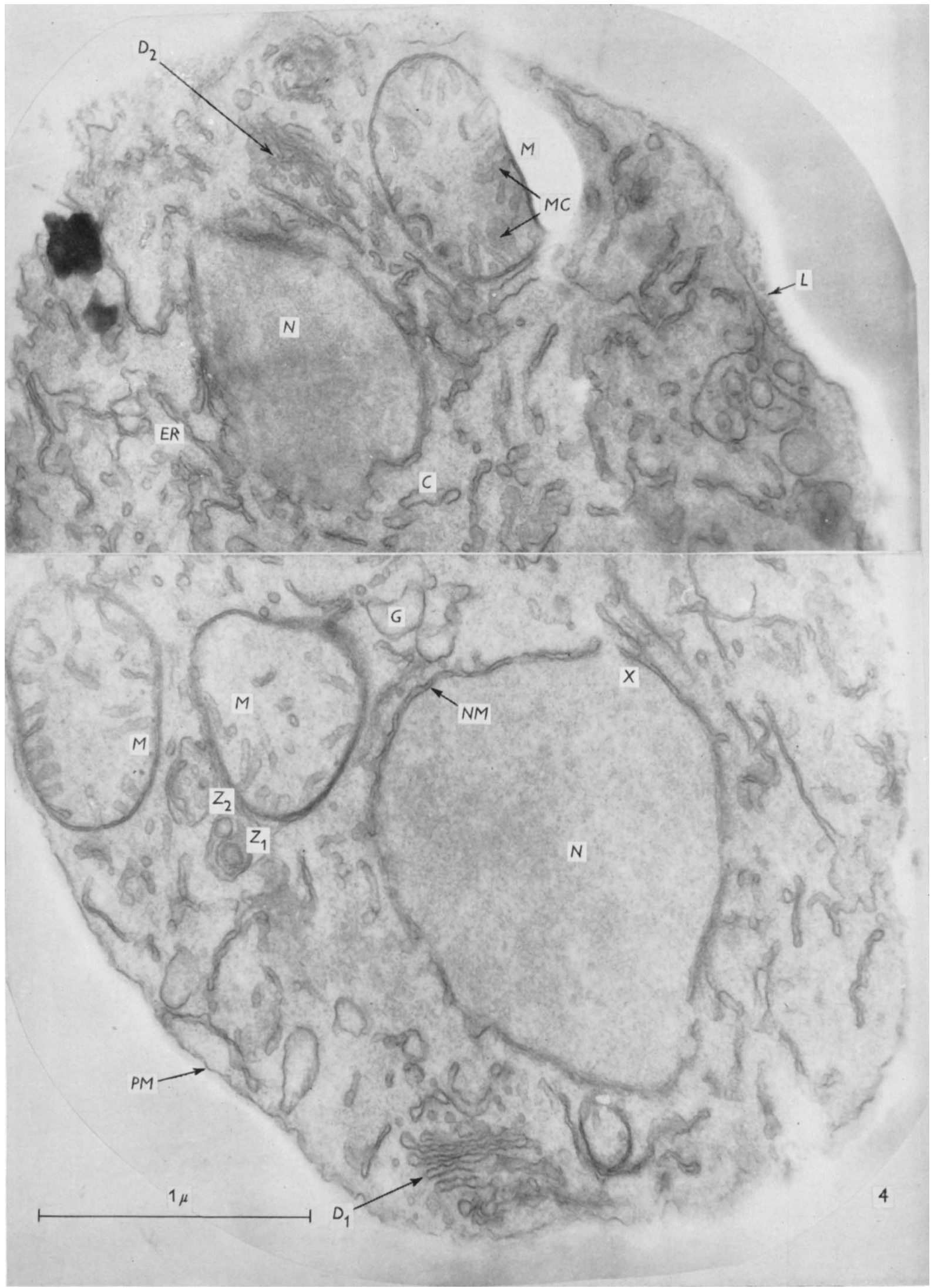




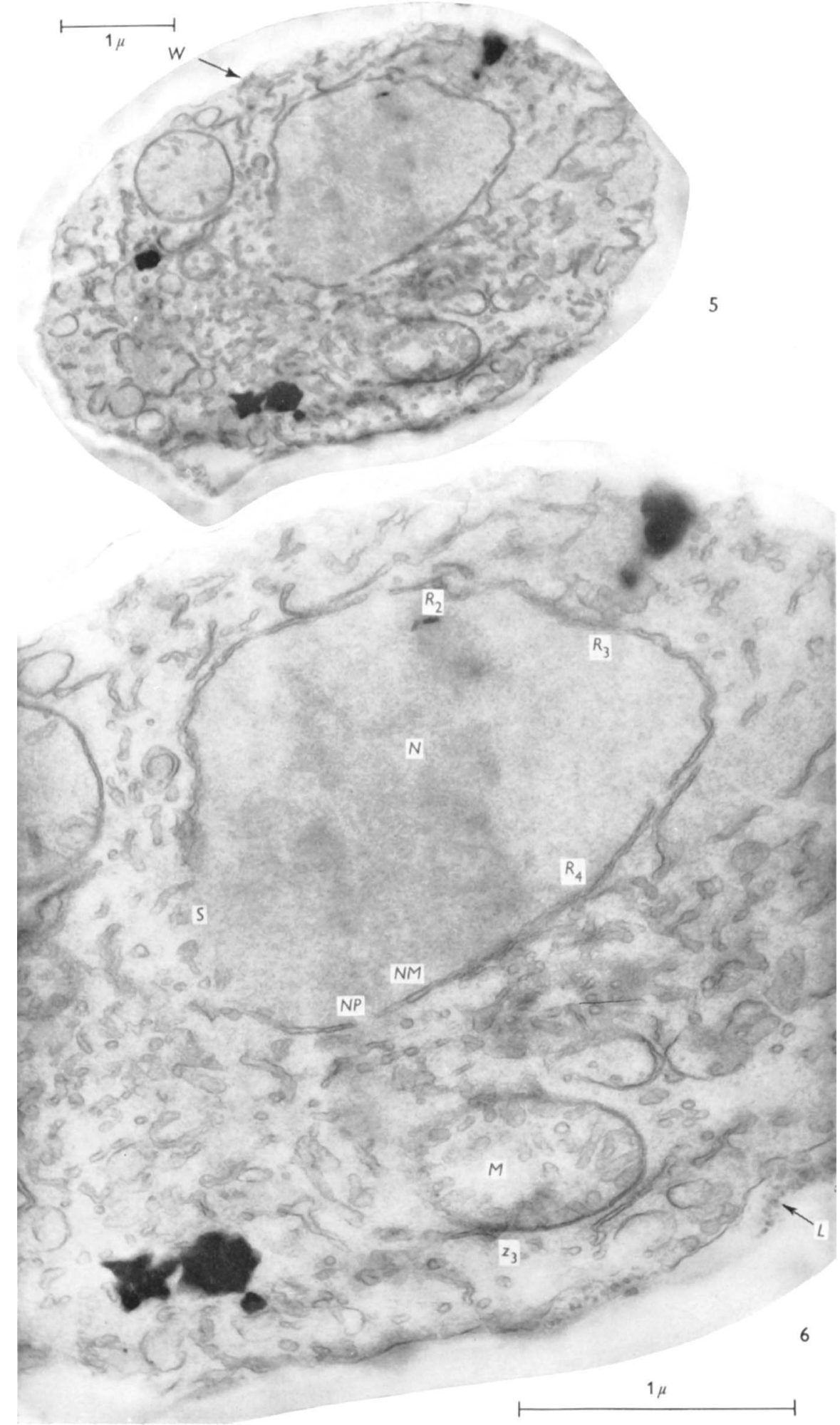




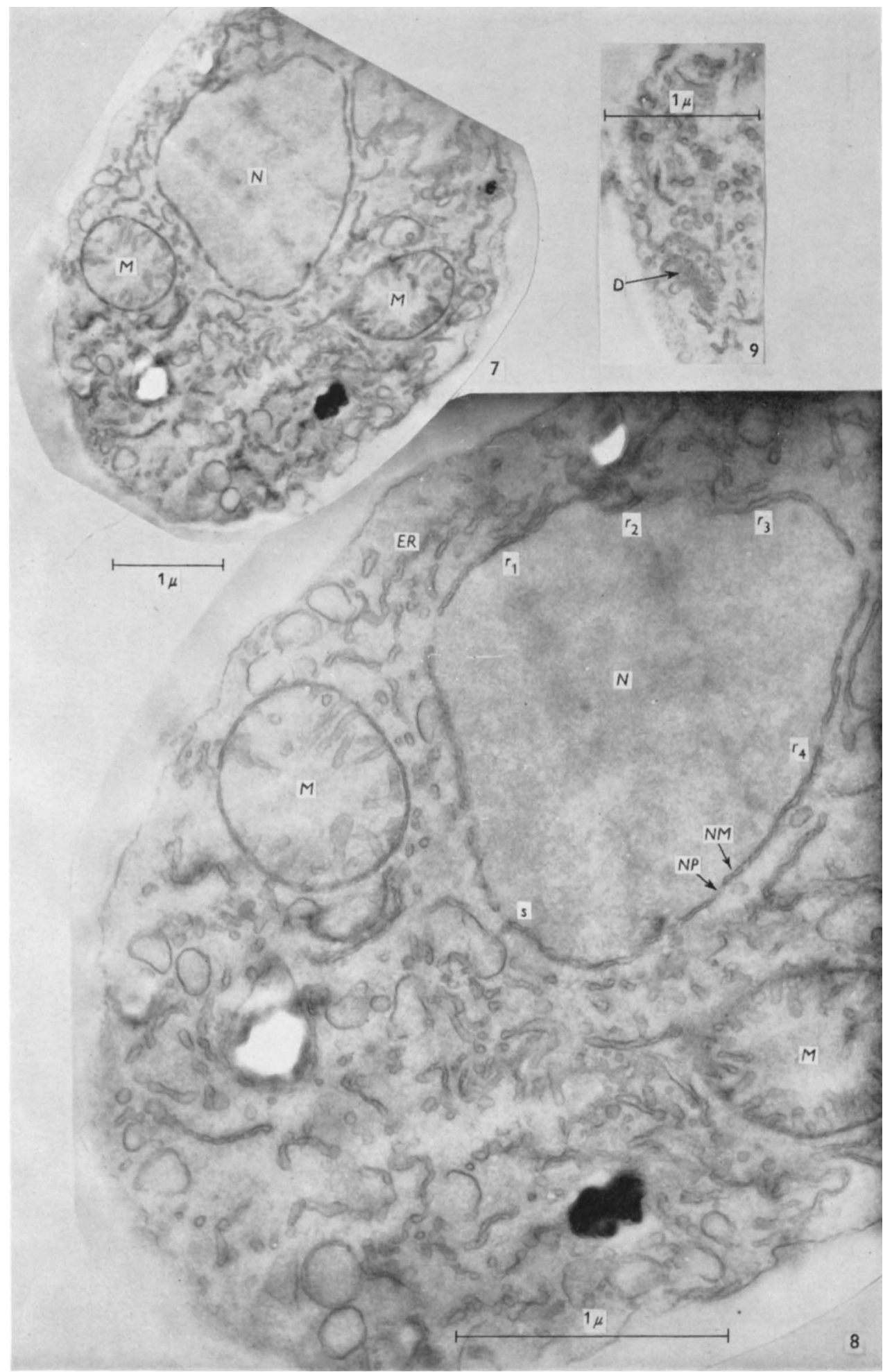

